\title{
Esophageal eosinophilia in children: A 6-year single-center experience
}

\author{
Murat Çakır ${ }^{1}$, Elif Sağ ${ }^{1}$, Sevdegül Mungan², Ulaş Emre Akbulut ${ }^{1}$, Fazıl Orhan ${ }^{3}$ \\ Departments of ${ }^{1}$ Pediatric Gastroenterology Hepatology and Nutrition, ${ }^{2}$ Pathology, ${ }^{3}$ Pediatric Allergy and Immunology, \\ Karadeniz Technical University Faculty of Medicine, Trabzon, Turkey. E-mail: muratcak@hotmail.com \\ Received: 6th March 2017, Revised: 30th March 2017-25th April 2017, Accepted: 1st May 2017
}

SUMMARY: Çakır M, Sağ E, Mungan S, Akbulut UE, Orhan F. Esophageal eosinophilia in children: A 6-year single-center experience. Turk J Pediatr 2017; 59: 369-378.

Esophageal eosinophilia (EE) and eosinophilic esophagitis (EoE) are emerging clinical entities, the prevalence of which has increased during the last 15 years. However, there is a lack of data concerning the etiology and outcomes of EE in children. The aim of this study was therefore to analyze the clinical findings and outcomes of children with EE and EoE in our pediatric gastroenterology unit over a 6-year period. The study included children undergoing esophagogastroduodenoscopy (EGD) during this 6-year period (January 2010 to December 2015) in our pediatric gastroenterology unit. The files of patients with EE were re-evaluated in detail to elicit demographic features, clinical, laboratory and histopathological findings, treatment modalities and outcomes. EE was determined in 33 patients [0.95\% (95\% CI: 0.63-1.27) among all children, and in $4.66 \%$ (95\% CI: 3.11-6.21) of children undergoing esophageal biopsy] $(8.6 \pm 4.2$ years and $72.7 \%$ male). EoE was the most common cause of EE $(n=11,33.3 \%)$, followed by eosinophilic gastroenteropathy $(n=6$, $18.1 \%)$ and proton pump inhibitor responsive esophageal eosinophilia $(n=4$, $12.1 \%)$. Patients with EoE $(n=11)$ were followed up for $21.2 \pm 18$ (range: 1-60) months, and treatment was discontinued in 2 patients (18.1\%). Additionally, 5 patients $(45.5 \%)$ received diet elimination only and 1 patient $(9 \%)$ received a combination of low dose steroids and diet. Three patients $(27.2 \%)$ are still being treated under the initial regimen. The overall incidence of EE increased in 2014-2015 compared to $2010-2011(0.41 \%$ vs. $1.33, p=0.047$, OR: 3.22 and $95 \%$ CI: $0.94-10.98, \mathrm{p}=0.06)$. EE is an increasingly common clinical entity with a wide spectrum of etiology and clinical presentations in children.

Key words: esophageal eosinophilia, children, etiology.

The presence of eosinophilic infiltrations in the squamous epithelium of the esophagus is an uncommon finding and may be associated with a variety of conditions in children, such as eosinophilic esophagitis (EoE), gastroesophageal reflux disease (GERD) and proton pump inhibitor responsive esophageal eosinophilia (PPI-REE). ${ }^{1}$ EoE is an emerging clinical entity, the prevalence of which has increased during the last 15 years, and one which requires intensive monitoring and treatment to prevent long-term complications. ${ }^{2}$ It has a complex pathogenesis, and both environmental factors and predisposed genetic backgrounds can lead to the disease. ${ }^{3}$ Diagnosis is based on the presence of eosinophil dominant inflammation $[\geq 15$ eosinophils per high power field (HPF) in $\geq 1$ esophageal biopsy] in addition to clinical symptoms related to esophageal dysfunction after exclusion of other causes of esophageal eosinophilia (EE). ${ }^{4}$ The true prevalence of the disease varies from region to region, the highest prevalence being reported in the United States and Austria, and a lower figure in the United Kingdom. ${ }^{5}$

The purpose of this study was to analyze the clinical findings, etiologies and outcomes of children with EE in our pediatric gastroenterology and allergy unit during a 6 -year period. Additionally, we focused on patients with EoE in terms of clinical and 
laboratory findings, treatment modalities and outcomes.

\section{Material and Methods}

This retrospective study was based on the findings in patients' hospital file records. Children undergoing esophagogastroduodenoscopy (EGD) during a 6-year period (from January 2010 to December 2015) in our pediatric gastroenterology unit were included $(n=3466)$. The files of patients with EE were re-evaluated in detail to elicit demographic features, clinical (major symptom at initial admission), laboratory and histopathological findings, treatment modalities and outcomes. EE was defined as the presence of eosinophils in the epithelium of the esophagus. ${ }^{4}$ Diagnosis of EoE, PPI-REE and other diseases was based on ACG Clinical Guidelines. ${ }^{4}$

Although we had planned to take at least three biopsies from the esophagus, stomach and duodenum during each endoscopy even if macroscopic appearances were normal, in practice this was not performed in the majority of cases (i.e., biopsy was taken only from the duodenum in cases with chronic diarrhea or only from the stomach in cases with dyspepsia). Esophageal biopsies were therefore obtained from only approximately $20 \%$ of the patients who underwent EGD $(n=708)$. Esophageal biopsy specimens from patients with EE were re-evaluated by a pathologist (SM). Peak intraepithelial eosinophil count (IEC) per HPF (400x, size of $1 \mathrm{HPF}-0.45 \times 0.45 \mathrm{~mm}$ ) and average IEC per HPF (at least $3 \mathrm{HPF}$ ) were analyzed in addition to other histopathological findings of $\mathrm{EE}$ and $\mathrm{EoE}$.

Following confirmation of EE after histopathological examination, all patients underwent atopy evaluation (history of physician-diagnosed atopic diseases, family history of atopic diseases and skin prick and/ or food-specific IgE blood test) by a pediatric allergist. Skin prick tests included common aeroallergens (Dermatophagoides pteronyssinus, Dermatophagoides farina, grass mix, Alternaria, Cladosporium and weeds) and food allergens (cow's milk, chicken egg, peanut, hazelnut, soy, wheat, rice, corn, chicken meat and beef). Additional food allergens were added to the skin prick test depending on the patient's clinical history and food intake. Histamine
(1 $\mathrm{mg} / \mathrm{ml}$ ) and saline were used for positive and negative controls. Tests were read after 15 minutes, and the prick test was considered positive if the widest diameter of the wheal was $\geq 3 \mathrm{~mm}$. The concentration of food specific IgEs was considered positive at a value $>0.35$ $\mathrm{kU} / \mathrm{L}$. Patients were considered to have allergen sensitization in the event of a positive skin prick test and/or specific IgE. Complete blood count analysis was used for the calculation of peripheral eosinophil count (PEC) (eosinophil\% $x$ total white blood cell count), and was considered elevated at a value $>300$ cells/ $\mathrm{mm}^{3}$. Total IgE was considered elevated when the levels were at upper limits for age and gender-specific values.

The treatment regimen employed was selected by the consulting physician. Generally, in patients with EE this depends on the underlying pathology (i.e., gluten free diet for celiac disease, and triple therapy for Helicobacter pylori gastritis). Patients with EoE underwent surgical dilatation if they had esophageal stricture. The six food elimination diet (SFED) or targeted elimination diet (TED) were used based on the atopic sensitization results. Topical (budesonide, 1-2 mg/day or fluticasone, 4 times 220-440 $\mu \mathrm{g}$ /day) or systemic corticosteroids (CS) (initial standard dose: $1 \mathrm{mg} / \mathrm{kg}$ for 2 weeks then tapered weekly and continued for 4-6 weeks; low dose: $0.5 \mathrm{mg} / \mathrm{kg}$ for 2 weeks, tapered to $0.25 \mathrm{mg} / \mathrm{kg}$ and continued for 6-8 weeks) were added to the treatment depending on the severity of the symptoms. At follow-up, CS was discontinued on the basis of amelioration of symptoms and/or histological improvement, and treatment continued with diet elimination only. Diet elimination was subsequently discontinued within 6 months based on the symptoms exhibited.

For clinical and other characteristics, continuous variables were expressed as mean and standard deviation, or median and range when appropriate. The chi-square test was used to compare the incidence of EE during three time periods (2010-2011, 2012-2013 and 2014-2015). A p value of $<0.05$ was considered significant. Approval for the study was obtained from the Ethics Committee of Karadeniz Technical University Faculty of Medicine (decision \# 2015/156). 


\section{Results}

EGD was performed on 3,466 children during the 6-year study period, and esophageal biopsy during EGD was obtained from 708 children $(20.4 \%)$. EE was determined in 33 patients [0.95\% (95\% CI: 0.63-1.27) among all the children enrolled, and in $4.66 \%$ (95\% CI: 3.11-6.21) of children undergoing esophageal biopsy (mean age \pm SD of the patients with $\mathrm{EE} ; 8.6 \pm 4.2$ years and $72.7 \%$ male).

The patients' main characteristics are shown in Table I. Chronic abdominal pain and acute villous atrophy. The patient was prescribed a gluten-free diet. One patient with EE (3\%) was admitted with chronic vomiting and recurrent oral aphthous lesions. Detailed personal history revealed recurrent fever attacks and a diagnosis of familial Mediterranean fever (FMF) based on clinical and positive MEFV mutation analysis. This patient was prescribed colchicine. One patient $(3 \%)$ with acute leukemia was admitted with acute solid food dysphagia while receiving maintenance treatment. Endoscopy revealed a 1/3 distal esophageal stricture. Esophageal biopsy revealed esophagitis and increased

Table I. Characteristics of 33 Patients with Esophageal Eosinophilia.

\begin{tabular}{lcc}
\hline Parameters & Number of patients $(\mathrm{n}=33)$ & $\%(95 \% \mathrm{CI})$ \\
\hline Age (year), mean \pm SD (range) & $8.6 \pm 4.2(1.5-17)$ & $72.7(57.5-87.9)$ \\
Male gender & 23 & $42.4(25.5-59.2)$ \\
Family history of atopic diseases & 14 & $54.5(37.5-71.4)$ \\
Allergen sensitization & 18 & $30.3(14.6-45.9)$ \\
$\quad$ Aeoroallergen & 10 & $33.3(17.2-49.3)$ \\
Food allergen & 11 & $42.4(25.5-59.2)$ \\
Atopic diseases & 14 & \\
Main symptomatology & & $45.4(28.4-62.3)$ \\
Chronic abdominal pain & 15 & $18.1(4.9-31.2)$ \\
Dysphagia/food impaction & 6 & $9.1(0-18.9)$ \\
Vomiting & 3 & $6(0-14.1)$ \\
Acute retrosternal pain & 2 & $9.1(0-18.9)$ \\
Chronic diarrhea & 3 & $6(0-14.1)$ \\
Feeding problems & 2 & $6(0-14.1)$ \\
Failure to thrive & 2 & $(18.9)$ \\
\hline
\end{tabular}

dysphagia/food impaction were the most common presenting symptoms. Allergen sensitization was determined in $54.5 \%$ of patients, and $42.4 \%$ of subjects had associated atopic diseases.

Two patients (6\%) with EE had severe and diffuse antral nodularity and exhibited positive Helicobacter pylori (H. pylori) staining at histological examination. Both were prescribed triple therapy (including proton pump inhibitor +2 antibiotics), and EE and H. pylori gastritis improved at histological examination after treatment. Six patients (18\%) had increased eosinophils in the duodenal and gastric biopsies in addition to EE. These subjects also had other clinical and laboratory findings of eosinophilic gastroenteropathy. One patient (3\%), admitted with chronic diarrhea, had elevated tissue transglutaminase IgA. Histopathological examination revealed $\mathrm{EE}$ in addition to total eosinophils (8 eos/HPF). Esophageal dilatation was performed, and PPI treatment was initiated.

Four of the other 22 patients were prescribed PPI before endoscopy, and were diagnosed with EoE based on clinical and histological findings. Eighteen patients were prescribed PPI (1-2 mg/ $\mathrm{kg}$ ) for 6 to 8 weeks. Thereafter, 13 underwent a second endoscopy, while five declined a second endoscopy or were lost to follow-up. Four patients responded to the PPI trial $(<5$ eos/ HPF), and PPI-REE was diagnosed. Seven out of 13 patients did not respond to the PPI trial $(\geq 15$ eos/HPF) and were diagnosed with EoE. Additionally, two patients who did not respond to the PPI trial ( $\geq 15$ eos/HPF) were diagnosed with PPI-nonresponsive GERD-related EE. One of these patients had severe motor and mental retardation, and barium esophagography revealed severe reflux and distal esophageal dilatation (lower esophageal sphincter failure). 
A trial of hydrolyzed formula was planned, but the patient died due to aspiration pneumonia. The other patient underwent anti-reflux surgery performed by a pediatric surgeon due to refractory reflux symptoms, and this subject had a high reflux index at 24-hour $\mathrm{pH}$ monitoring. EE and esophageal symptoms improved after reflux surgery. Both patients were negative for the skin prick test and specific IgE testing. Final diagnoses are shown in Figure 1a and $1 \mathrm{~b}$.
(18.1\%), while 3 patients $(27.2 \%)$ had whitish exudates/plaques, 2 (18.1\%) had linear furrows, $2(18.1 \%)$ had trachealization and one $(9 \%)$ had esophageal polyp and ringed esophagus/ stenosis. Peak and average IEC values were $40.2 \pm 32.4$ (range: $15-125$ ) and $31.1 \pm$ 21.7 (range: 12-105) eos/HPF, respectively. Eosinophilic micro-abscess was determined in one patient $(9 \%)$.

The treatment regimens and outcomes of the

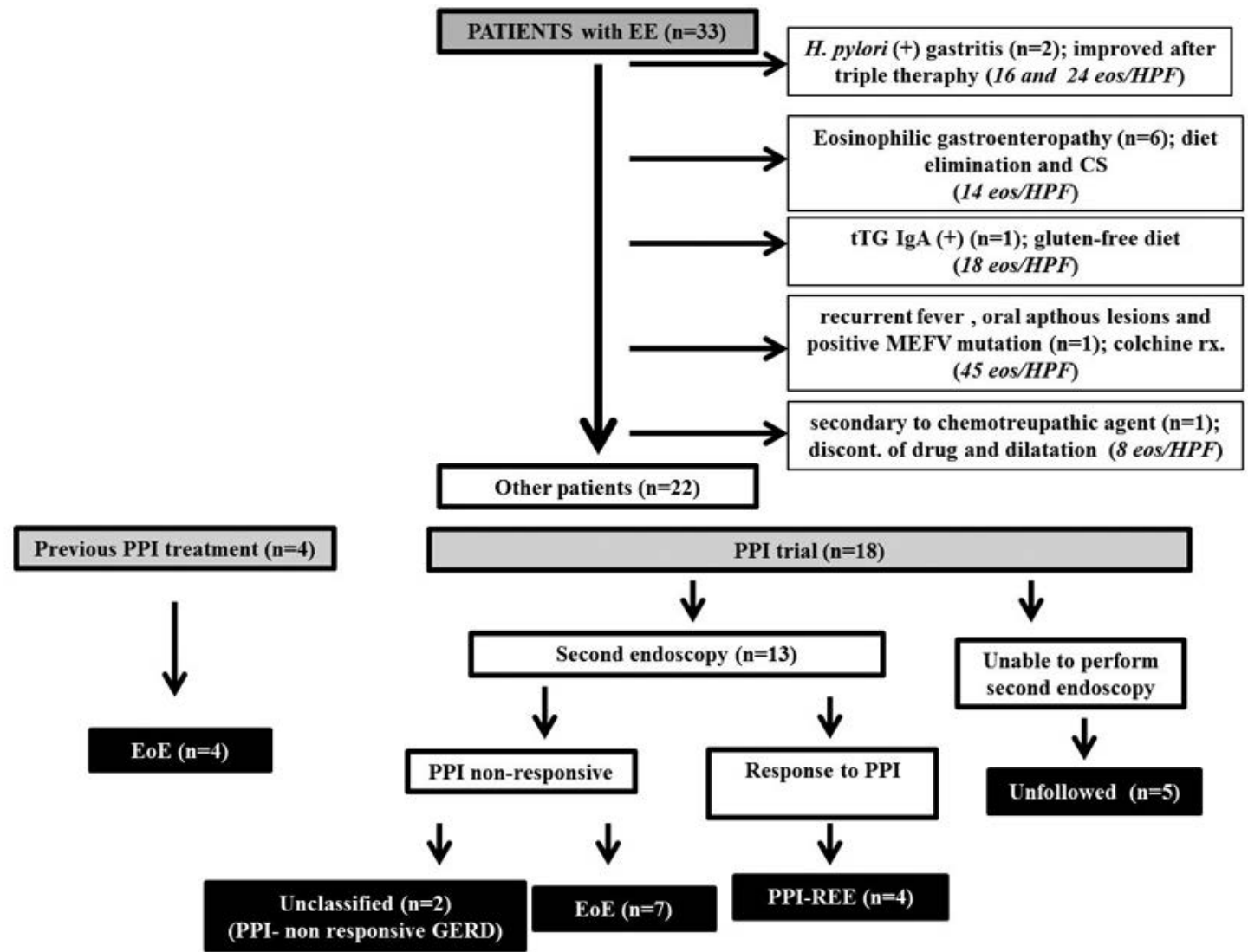

Fig. 1a. Outcome of the patients with EE. Eosinophil counts in the parenthesis showed the average IEC. EE: eosinophilic eosinophilia, EoE: eosinophilic esophagitis, eos/HPF: eosinophils/high power field, GERD: gastroesophageal reflux disease, IEC: intraepithelial eosinophil count, MEFV: Mediterranean Fever, PPI: proton pump inhibitor, PPI-REE: proton pump inhibitor responsive eosinophilic eosinophilia, tTG IgA:tissue transglutaminase immunoglobulin A.

Demographic features, and clinical and laboratory findings of the patients with EoE $(n=11)$ are shown in Table II. The patients' mean age was $6.3 \pm 3.9$ years (1.5-13), and $81.8 \%$ were male. Peripheral eosinophilia and elevated serum total IgE were determined in $90.9 \%$ and $54.5 \%$ of patients, retrospectively. Allergen sensitization and atopic diseases were determined in $81.8 \%$ and $54.5 \%$ of patients, respectively. In addition, $45.4 \%$ of patients presented with acute dysphagia/food impaction. Endoscopic imaging was normal in 2 patients patients with EoE are shown in Figure 2. The regimens included SFED $(\mathrm{n}=5)$ or TED $(n=4)$ in combination with CS. Patients were given only CS when atopy tests were negative $(\mathrm{n}=2)$. Additionally, esophageal dilatation was performed in one case due to esophageal stricture. Topical CS was used in six cases and systemic CS in five. Patients were followedup for $21.2 \pm 18$ (range: 1-60) months, and treatment was discontinued in 2 patients $(18.1 \%)$. Five patients $(45.4 \%$, SFED in four and TED in one) received only diet elimination, 


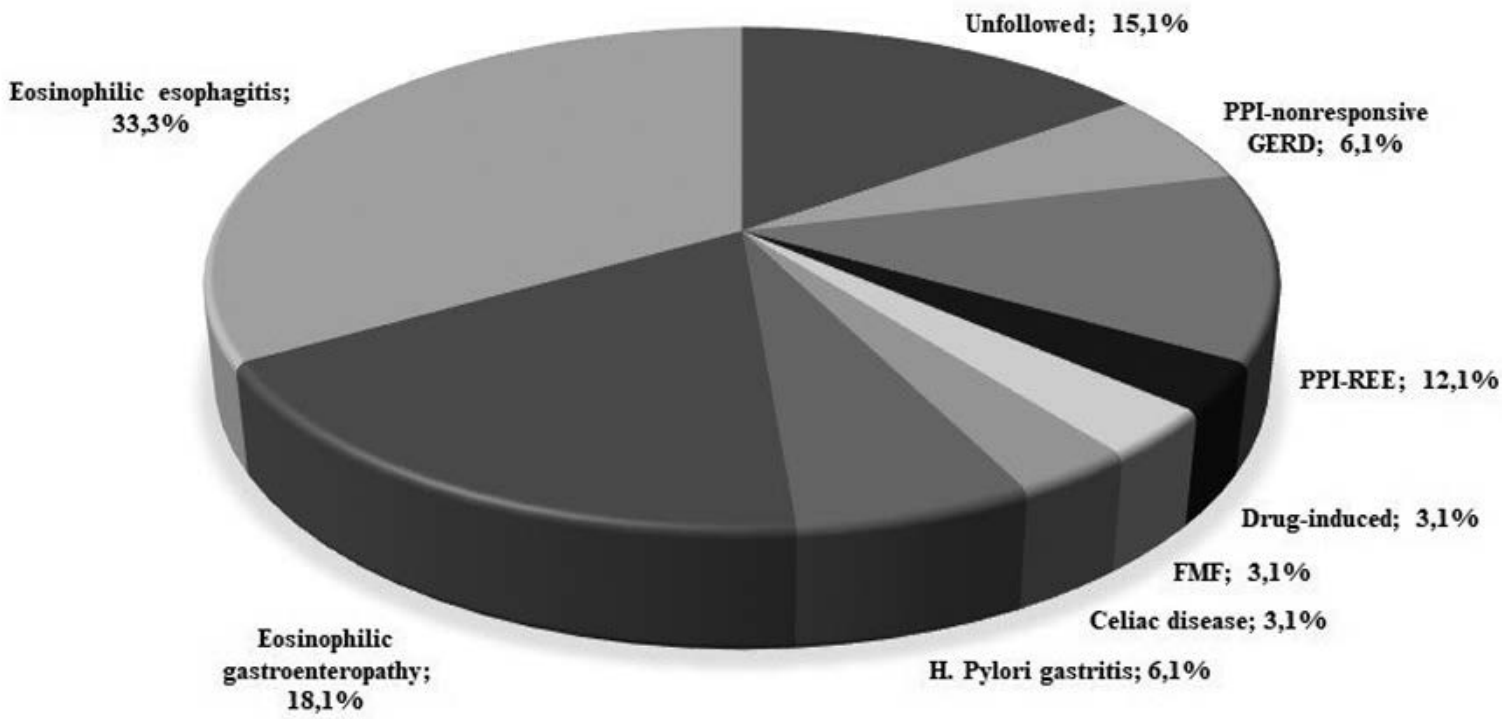

Fig. 1b. Final diagnosis of the patients with EE. EE: eosinophilic eosinophilia, FMF: familial Mediterranean fever, GERD: gastroesophageal reflux disease, PPI: proton pump inhibitor, PPI-REE: proton pump inhibitor responsive eosinophilic eosinophilia.

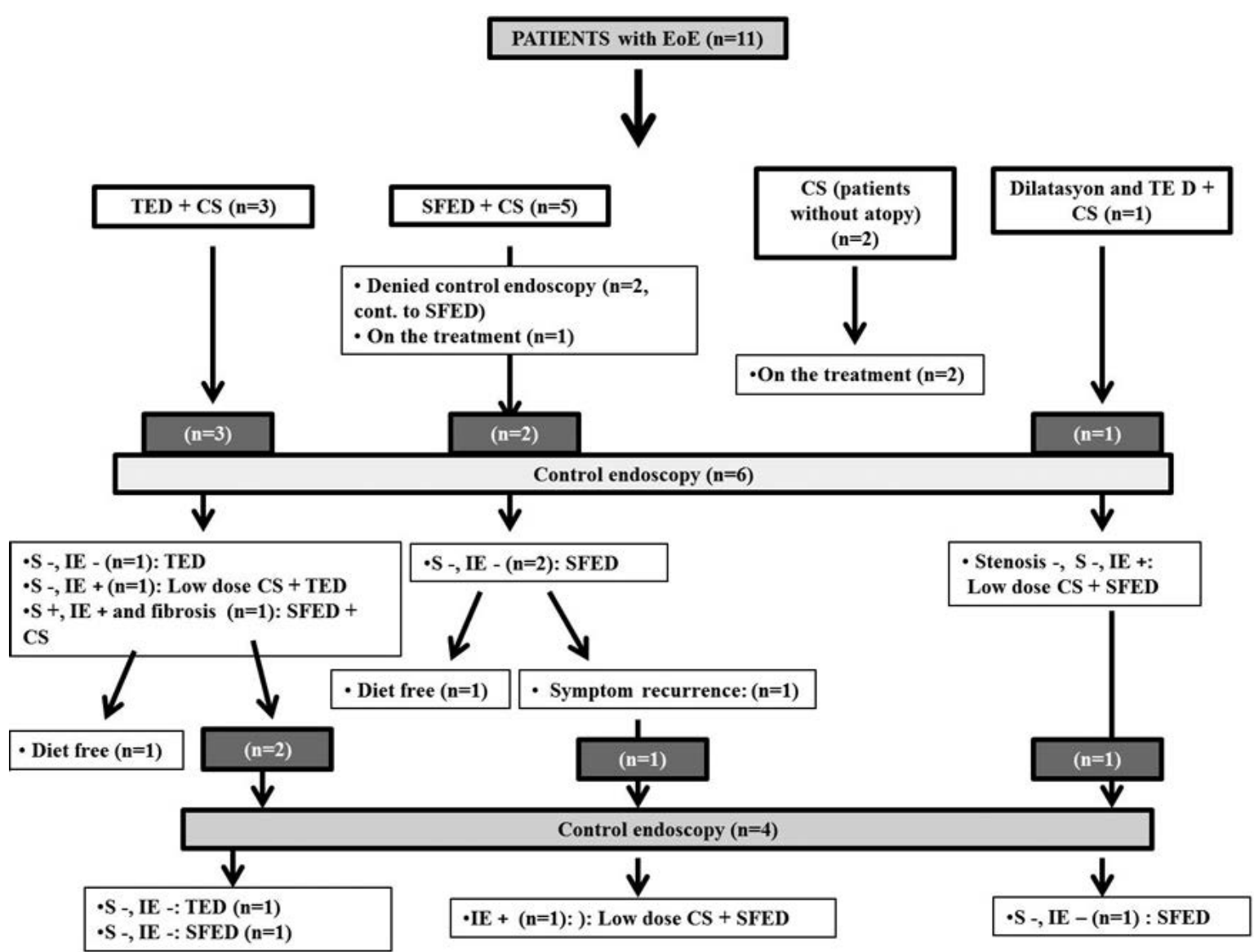

Fig. 2. Outcome of the patients with EoE. $S$-: symptom free, $S+$ : symptoms persist, IE +: increased intraepithelial eosinophil count, IE -: decreased intraepithelial eosinophil count. CS: corticosteroids, EoE: eosinophilic esophagitis, SFED: six food elimination diet, TED: targeted elimination diet. 


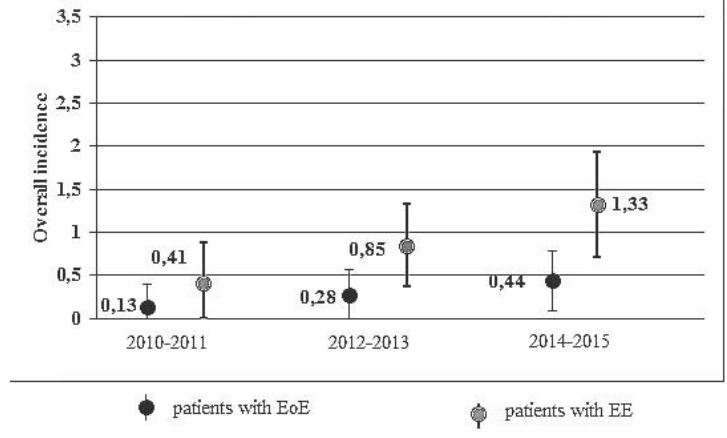

Fig. 3. Incidence of $E E$ and EoE according to three time-span. Note the increment is statistically significant in patients with EE between 2010-2011 and 2014-2015 $(p=0.041)$. Upper and lower bar represent the $95 \%$ CI. EE: eosinophilic eosinophilia, EoE: eosinophilic esophagitis. and one patient $(9 \%)$ received a combination of low-dose CS and diet (SFED). Three patients $(27.2 \%)$ are still being treated under the initial regimen.

The incidence of EE for the three time periods in the previous 6 years is shown in Table III. The overall incidence of EE increased in 20142015 compared to $2010-2011$ (0.41\% vs. 1.33 , $\mathrm{p}=0.047$ and OR: 3.12 ). At subgroup analysis, the overall incidence of EoE increased gradually over the three time periods, but this did not reach statistical significance $(0.13 \%, 0.28 \%$ and $0.44 \%$, respectively and $\mathrm{p}>0.05$ ) (Fig. 3 ).

\section{Discussion}

This study describes (i) the clinical characteristics and diseases associated with EE, (ii) clinical, laboratory and histological

Table II. Demographic Features, Clinical and Laboratory Findings of the Patients $(n=11)$ with Eosinophilic Esophagitis

\begin{tabular}{|c|c|c|}
\hline Parameters & Results & $\%(95 \% \mathrm{CI})$ \\
\hline Age (year), mean \pm SD (range) & $6.3 \pm 3.9(1.5-13)$ & \\
\hline Male gender & 9 & $81.8(59-100)$ \\
\hline $\mathrm{PEC}$, mean $\pm \mathrm{SD}$ (range) cells $/ \mu \mathrm{L}$ & $711.1 \pm 362.8(150-1300)$ & \\
\hline Peripheral eosinophilia & 10 & $90.9(73.9-100)$ \\
\hline Total IgE, mean \pm SD (range) & $756.7 \pm 851.3(69-2500)$ & \\
\hline Increased total IgE & 6 & $54.5(25-83.9)$ \\
\hline Allergen sensitization & 9 & $81.8(59-100)$ \\
\hline Food allergen & 9 & $81.8(59-100)$ \\
\hline Cow's milk & 7 & $63.6(35.1-92)$ \\
\hline Hen's egg & 4 & $36.3(7.8-64.7)$ \\
\hline Soy & 4 & $36.3(7.8-64.7)$ \\
\hline Hazelnut & 3 & $27.2(0.9-53.5)$ \\
\hline Peanut & 2 & $18.1(0-40.8)$ \\
\hline Wheat & 2 & $18.1(0-40.8)$ \\
\hline Kiwi & 2 & $18.1(0-40.8)$ \\
\hline Walnut & 2 & $18.1(0-40.8)$ \\
\hline Aeroallergen & 4 & $36.3(7.8-64.7)$ \\
\hline Acute dysphagia/food impaction & 5 & $45.4(15.9-74.8)$ \\
\hline \multirow{2}{*}{\multicolumn{3}{|c|}{ Endoscopic feature }} \\
\hline & & \\
\hline Linear furrows & 2 & $18.1(0-40.8)$ \\
\hline Whitish exudates/plaques & 3 & $27.2(0.9-53.5)$ \\
\hline Trachealization & 2 & $18.1(0-40.8)$ \\
\hline Esophageal polyp & 1 & $9(0-25.9)$ \\
\hline Ringed esophagus/stenosis & 1 & $9(0-25.9)$ \\
\hline $\mathrm{IEC}$, mean $\pm \mathrm{SD}$ (range) eos/HPF & 2 & $18.1(0-40.8)$ \\
\hline Peak & $40.2 \pm 32.4(15-125)$ & \\
\hline Average & $31.1 \pm 21.7(12-105)$ & \\
\hline Eosinophilic microabcess & 1 & $9(0-25.9)$ \\
\hline Superficial layering of eosinophils & 2 & $18.1(0-40.8)$ \\
\hline
\end{tabular}

HPF: high-power field, IEC: intraepithelial eosinophil count, PEC: peak eosinophil count. 
Table III. Incidence of Esophageal Eosinophilia (EE) and Eosinophilic Esophagitis (EoE) According to Three Time Span in the Last 6-years.

\begin{tabular}{lcccc}
\hline Parameters & $2010-2011$ & $2012-2013$ & $2014-2015$ & Overall \\
\hline Number of children with EGD & 717 & 1403 & 1346 & 3466 \\
Number of esophageal biopsy & 54 & 290 & 374 & 708 \\
Percent of esophageal biopsy & 7.5 & 20.6 & 27.7 & 20.4
\end{tabular}

Number of children with EoE Incidence of EoE, (95\% CI)

Biopsy performed Overall

Number of children with EE Incidence of $\mathrm{EE}$, (95\% CI) Biopsy performed Overall
12

$4.13(1.84-6.42)$

$0.85(0.37-1.33)$
$1.37(0.03-2.71)$
$0.28(0-0.56)$ $\begin{array}{cc}1.6 & (0.33-2.87) \\ 0.44 & (0.09-0.79)\end{array}$
$1.55(0.64-2.46)$ $0.31(0.12-0.5)$

$\mathrm{p}^{\mathrm{a}-\mathrm{b}}=0.047$ (OR: 3.22 and 95\% CI: 0.94-10.98, p: 0.06). EGD: esophagogastroduodenoscopy.

findings and outcomes of EoE in children and (iii) changing incidences of EE during a 6-year period.

Apart from EoE, GERD and PPI-REE, excessive accumulation of eosinophils in esophageal tissue has been shown in numerous disorders, such as celiac disease (CD), eosinophilic gastrointestinal disease, inflammatory bowel disease, achalasia, drugs, vasculitis and infections, as in our cases. ${ }^{1,4}$ An association between EE and $\mathrm{CD}$ has previously been described in adult and pediatric reports. ${ }^{1,6,7}$ Quaglietta $\mathrm{L}$ et al. ${ }^{6}$ reported $\mathrm{CD}$ in six out of 17 pediatric patients $(35.2 \%)$ with EoE, and stated that histological and clinical improvement were seen after a gluten-free diet. In contrast, an increased prevalence of EoE in patients with $\mathrm{CD}$ has also been reported in pediatric patients. ${ }^{7}$ These two disorders are caused by aberrant immune response, and diet elimination improved the symptoms in both. The association might be related to the effect of gluten on esophageal mucosal integrity. ${ }^{8}$ Despite these reports, the association between these two disorders has not been confirmed in large population-based epidemiological studies. ${ }^{9} \mathrm{H}$. pylori gastritis has been determined in $6 \%$ of children with EE, a lower figure than in population-based $H$. pylori prevalence studies. ${ }^{10}$ An inverse association has been reported between $H$. pylori infection and EE in previous pediatric studies. ${ }^{11,12} \mathrm{H}$. pylori infection reduces the development of atopy by approximately $20 \%$, which is protective against IgE mediated reactions. ${ }^{13}$ No association between EE with FMF has previously been reported. However, Gurkan OE et al. ${ }^{14}$ reported a case of esophagitis and widespread aphthous ulcerations in gastric mucosa in an infant with FMF. Improvement of clinical symptoms after treatment proved that this is related to FMF. Esophageal stricture and EE may rarely be seen secondary to anti-neoplastic agents, such as doxorubicin, methotrexate, and cytosine arabinoside, either alone or in combination with radiotherapy. Mild mucosal eosinophilia may be seen in addition to eosophagitis. ${ }^{15}$

Unresponsiveness to PPI therapy is the mainstay for differentiating EoE from GERD and PPIREE according to recent guidelines. ${ }^{16} \mathrm{~A}$ small number of patients with GERD may present with EE due to (i) epithelial tight junction damage secondary to gastric acid exposure, which may allow the allergen penetration that may subsequently trigger eosinophilic infiltration, while (ii) GERD and EE may coexist in a patient without being related to one another, and (iii) EE may cause GERD due to esophageal dysfunction. PPIs have beneficial effects on EE in these patients through (i) antiinflammatory and (ii) antioxidant effects and (iii) by blocking the IL-4 and IL-13 stimulated secretion of eotaxin-3. ${ }^{17}$ Approximately onethird of patients with EE respond to PPI therapy. Despite the guidelines and studies, the PPI trial in the management of EE is still to some extent controversial. Two of our patients did not respond to the PPI trial, and both were negative for the skin prick 
test and specific IgE testing. One had severe mental motor retardation and severe reflux and distal esophageal dilatation at barium esophagography, and the other had a high reflux index at 24-hour $\mathrm{pH}$ monitoring. One underwent anti-reflux surgery, and both the symptoms and histology improved thereafter. These two patients are unlikely to have had EoE because they were negative for allergy testing and had radiological and laboratory findings compatible with severe GERD. We think that the PPI trial may fail to differentiate EoE and GERD in some patients, especially when GERD is severe.

The main clinical characteristics of EoE are adolescent age, male sex, presence of atopy, dysphagia/food impaction, trachealization, white papules and furrowing. The presenting symptoms and other findings in our patients are in agreement with previous studies. ${ }^{18,19}$ As reported previously, endoscopic appearance may be normal and clinical findings may be non-specific in some cases, and patients may be diagnosed incidentally at histological examination. ${ }^{16,18,19}$ Mucosal biopsy during endoscopy from at least two levels is currently recommended, even though the macroscopic appearance of the mucosa is normal. Approximately $80 \%$ of our patients had $\geq 1$ specific allergen confirmed by skin prick tests and specific IgEs. We were unable to perform the skin patch test in our patient group, but the rate of atopy was similar to those in previous studies. ${ }^{20,21}$ Aeroallergens were determined in approximately $35 \%$ of our patients. Levels of $10 \%$ to $20 \%$ have been reported in previous studies. ${ }^{21}$ Aeroallergens have been shown to be associated with seasonal variation in clinical admissions in previous studies. ${ }^{21}$

As with other allergic diseases, the incidence of EE seems to have increased during recent decades. ${ }^{4,5}$ It is difficult to estimate the true incidence of EE, because esophageal biopsy is the gold standard for diagnosis. The availability of endoscopic evaluation for gastrointestinal problems in children is increasing in all centers in Turkey, and with the increased rate of esophageal biopsy, this will reveal the true incidence of the disease in the next few years. In our study, the overall incidence of EE increased in 2014-2015 compared to 2010-2011. Unfortunately, our results did not show the true prevalence since esophageal biopsy was not performed in all cases, but our findings may still provide a rough overview. Similar problems have been reported in previous prevalence studies for the same reason. ${ }^{22-24}$ Memon $\mathrm{Z}$ et al. ${ }^{25}$ analyzed childhood esophagitis over a period of 30 years and observed that the incidence of EE (>25/HPF) had increased in 2011 compared to 1980-1988 and 2000-2002. Soon IS et al. ${ }^{5}$ searched the literature for the incidence and prevalence of EoE in children and reported that both had increased significantly over the previous two decades. Homan $\mathrm{M}$ et al. ${ }^{19}$ observed a similar increase in Slovenian children. Many studies have suggested that the prevalence of the disease is increasing, but whether the increased prevalence is real or due to increased use of endoscopic procedures and increased awareness of the disease is still the subject of debate. ${ }^{26}$ Prospective well-designed studies will elicit the true prevalence of EE in children.

Treatment modalities for EoE include diet and/or CS.27,28 Personalized treatment regimens depending on the presence of allergic desensitization and disease behavior have been generally preferred in recent years. Elemental diet, SFED and TED have been prescribed in previous studies, and elemental diet has been shown to be superior at inducing remission compared to SFED and TED, but is less palatable. ${ }^{28-31}$ Similar histological improvement has been reported in TED and SFED in previous pediatric studies, but TED is commonly preferred since this involves the elimination of less food. On the other hand, there are some limitations to the usefulness of the skin prick/ patch test and specific IgE levels in planning TED. These tests are sometimes unable to detect casual food allergens. ${ }^{31,32}$ In one of our cases, which was reported negative for cow's milk by the skin prick test and specific IgE analysis, TED was prescribed initially, but control endoscopy revealed increased IEC and esophageal fibrosis. SFED was then prescribed, and histological improvement was achieved. CS is generally used for induction in severe EoE, in patients who are unable to tolerate diet restriction and in patients who are negative for allergen sensitization. Low-dose CS may be used for maintenance treatment, but side-effects such as adrenal suppression, bone diseases, and candidiasis should also be considered. ${ }^{33}$ 
EE is a long-term disease, and recurrences may be seen in some patients. Discontinuation of treatment is therefore difficult, and patients are generally prescribed diet restrictions, PPI or low-dose CS in the long term. ${ }^{34} \mathrm{We}$ were able to discontinue treatment in only 2 patients $(18.1 \%)$, while the others continued on diet restriction and/or medical treatment. Similar results were reported by Homan $\mathrm{M}$ et al. ${ }^{19}$ who determined complete symptomatic and histological remission in $20 \%$ of children after all medications and diet restrictions had been stopped.

The limitations of our study are as follows: (i) as mentioned above, esophageal biopsy could not be obtained from all children, so our results do not represent the true incidence of EE, and (ii) deep mucosal biopsy is needed for the assessment of mucosal eosinophilia, and esophageal biopsy was not sufficiently large for the assessment of eosinophilia in a significant number of patients. Further prospective studies with deep mucosal biopsies taken from all patients are now needed to analyze the true incidence of EE. (iii) Although the incidence of allergic sensitization was similar to those in previous studies, the skin patch test was required in patients without allergic sensitization.

In conclusion, $\mathrm{EE}$ is an increasing clinical entity with a wide spectrum of etiology and clinical presentations in children.

\section{REFERENCES}

1. Lucendo AJ. Disease associations in eosinophilic oesophagitis and oesophageal eosinophilia. Best Pract Res Clin Gastroenterol 2015; 29: 759-769.

2. Papadopoulou A, Dias JA. Eosinophilic esophagitis: an emerging disease in childhood - review of diagnostic and management strategies. Front Pediatr 2014; 2 : 129.

3. Leung J, Beukema KR, Shen AH. Allergic mechanisms of eosinophilic oesophagitis. Best Pract Res Clin Gastroenterol 2015; 29: 709-720.

4. Dellon ES, Gonsalves N, Hirano I, Dellon ES, Gonsalves N, Hirano I; American College of Gastroenterology. ACG clinical guideline: Evidenced based approach to the diagnosis and management of esophageal eosinophilia and eosinophilic esophagitis (EoE). Am J Gastroenterol 2013; 108: 679-692.

5. Soon IS, Butzner JD, Kaplan GG, deBruyn JC. Incidence and prevalence of eosinophilic esophagitis in children. J Pediatr Gastroenterol Nutr 2013; 57: 72-80.
6. Quaglietta L, Coccorullo P, Miele E, Pascarella F Troncone R, Staiano A. Eosinophilic oesophagitis and coeliac disease: is there an association? Aliment Pharmacol Ther 2007; 26: 487-493.

7. Thompson JS, Lebwohl B, Reilly NR, Talley NJ, Bhagat G, Green PH. Increased incidence of eosinophilic esophagitis in children and adults with celiac disease. J Clin Gastroenterol 2012; 46: e6-11.

8. Pinto-Sánchez MI, Nachman FD, Fuxman C, et al Altered esophageal mucosal structure in patients with celiac disease. Can J Gastroenterol Hepatol 2016; 2016: 1980686.

9. Ludvigsson JF, Aro P, Walker MM, et al. Celiac disease, eosinophilic esophagitis and gastroesophageal reflux disease, an adult population-based study. Scand J Gastroenterol 2013; 48: 808-814.

10. Çınar A, Sadıç M, Atılgan HI, et al. Prevalence of Helicobacter pylori infection in school and pre-school aged children with $\mathrm{C}-14$ urea breath test and the association with familial and environmental factors. Mol Imaging Radionucl Ther 2015; 24: 66-70.

11. Dellon ES, Peery AF, Shaheen NJ, et al. Inverse association of esophageal eosinophilia with Helicobacter pylori based on analysis of a US pathology database. Gastroenterology 2011; 141: 1586-1592.

12. Elitsur Y, Alrazzak BA, Preston D, Demetieva Y. Does Helicobacter pylori protect against eosinophilic esophagitis in children? Helicobacter 2014; 19: 367371.

13. Taye B, Enquselassie F, Tsegaye A, Medhin G, Davey G, Venn A. Is Helicobacter pylori infection inversely associated with atopy? A systematic review and metaanalysis. Clin Exp Allergy 2015; 45: 882-890.

14. Gurkan OE, Fidan K, Dalgic B. Esophagitis and widespread aphthous ulcerations in gastric mucosa in an infant with familial Mediterranean fever. J Pediatr Gastroenterol Nutr 2014; 59: 11-13.

15. Ishimaru D, Ohno T, Maeda M, Nishimoto Y, Shimizu $\mathrm{K}$. Chemotherapy-induced oesophageal stricture in a child with osteosarcoma: a case report. Chemother Res Pract 2010; 2010: 240763.

16. Papadopoulou A, Koletzko S, Heuschkel R, et al ESPGHAN Eosinophilic Esophagitis Working Group and the Gastroenterology Committee. Management guidelines of eosinophilic esophagitis in childhood. J Pediatr Gastroenterol Nutr 2014; 58: 107-118.

17. Wolf WA, Dellon ES. Eosinophilic esophagitis and proton pump inhibitors: Controversies and implications for clinical practice. Gastroenterol Hepatol (NY) 2014; 10: 427-432.

18. Mulder DJ, Hurlbut DJ, Noble AJ, Justinich CJ. Clinical features distinguish eosinophilic and reflux-induced esophagitis. J Pediatr Gastroenterol Nutr 2013; 56: 263-270.

19. Homan M, Blagus R, Jeverica AK, Orel R. Pediatric eosinophilic esophagitis in Slovenia: Data from a retrospective 2005-2012 epidemiological study. J Pediatr Gastroenterol Nutr 2015; 61: 313-318. 
20. Gómez Torrijos E, Sánchez Miranda P, Donado Palencia $\mathrm{P}$, et al. Eosinophilic esophagitis: Demographic, clinical, endoscopic, histological and allergological characteristics in children and teenagers in a region of central Spain. J Investig Allergol Clin Immunol 2016; 10: 104-110.

21. Spergel JM. An allergist's perspective to the evaluation of eosinophilic esophagitis. Best Pract Res Clin Gastroenterol 2015; 29: 771-781.

22. Cherian S, Smith NM, Forbes DA. Rapidly increasing prevalence of eosinophilic oesophagitis in Western Australia. Arch Dis Child 2006; 91: 1000-1004.

23. Pulcini JM, Nowicki M, Roy S. Increasing prevalence of eosinophilic esophagitis in the pediatric population of Mississippi. J Allergy Clin Immunol 2010; AB632.

24. Dantuluri S. Eosinophilic esophagitis: Are we missing it? J Pediatr Gastroenterol Nutr 2019; 48: E143.

25. Memon Z, Baker RD, Khan A, Baker SS. Childhood esophagitis changes in 30 years at 1 center. J Pediatr Gastroenterol Nutr 2015; 61: 538-540.

26. Prasad GA, Alexander JA, Schleck CD, et al. Epidemiology of eosinophilic esophagitis over three decades in Olmsted County, Minnesota. Clin Gastroenterol Hepatol 2009; 7: 1055-1061.
27. Sodikoff J, Hirano I. Therapeutic strategies in eosinophilic esophagitis: Induction, maintenance and refractory disease. Best Pract Res Clin Gastroenterol 2015; 29: 829-839.

28. Kagalwalla AF. Dietary treatment of eosinophilic esophagitis in children. Dig Dis 2014; 32: 114-119.

29. Straumann A. Medical therapy in eosinophilic oesophagitis. Best Pract Res Clin Gastroenterol 2015; 29: 805-814.

30. Markowitz JE, Spergel JM, Ruchelli E, Liacouras CA. Elemental diet is an effective treatment for eosinophilic esophagitis in children and adolescents. Am J Gastroenterol 2003; 98: 777-782.

31. Henderson CJ, Abonia JP, King EC, et al. Comparative dietary therapy effectiveness in remission of pediatric eosinophilic esophagitis. J Allergy Clin Immunol 2012; 129: $1570-1578$.

32. Spergel JM, Brown-Whitehorn TF, Cianferoni A, et al. Identification of causative foods in children with eosinophilic esophagitis treated with an elimination diet. J Allergy Clin Immunol 2012; 130: 461-467.

33. Contreras EM, Gupta SK. Steroids in pediatric eosinophilic esophagitis. Gastroenterol Clin North Am 2014; 43: 345-356.

34. Menard-Katcher P, Marks KL, Liacouras CA, Spergel JM, Yang YX, Falk GW. The natural history of eosinophilic oesophagitis in the transition from childhood to adulthood. Aliment Pharmacol Ther 2013; 37: 114-121. 